\title{
O bugio (Alouatta caraya) no contexto do turismo de observação de vida silvestre no Pantanal Sul, Brasil
}

\author{
The howler monkey (Alouatta caraya) in the context of wildlife tourism in Southern Pantanal, Brazil \\ El mono aullador (Alouatta caraya) en el contexto del turismo de observación de vida salvage en Pantanal del Sur, \\ Brasil
}

Simone Mamede

Instituto Mamede de Pesquisa Ambiental de Ecoturismo,

Brasil

simone.mamede1@gmail.com

Maristela Benites

Universidade Federal do Mato Grosso do Sul, Brasil

maris.benites@gmail.com

Cleber José Rodrigues Alho

Universidade para o Desenvolvimento do Estado e Região

do Pantanal, Brasil

alhocleber@gmail.com
DOI: https://doi.org/10.18472/cvt.21n3.2021.1845 Redalyc: https://www.redalyc.org/articulo.oa? id $=115469516003$

Recepción: 08 Agosto 2020

Aprobación: 15 Junio 2021

\section{Resumo:}

O presente trabalho teve por objetivo avaliar como o bugio (Alouatta caraya) está inserido no contexto do turismo de observação de vida silvestre no Pantanal Sul e seu reconhecimento enquanto espécie-bandeira, além de pautar recomendações para o ecoturismo na região pantaneira. A área de estudo contempla a região do Pantanal sul-mato-grossense. Para a coleta de dados foi aplicado um formulário semiestruturado aos turistas que visitaram o Pantanal Sul e moradores locais da região do Passo do Lontra (Pantanal do Miranda) e da Curva do Leque (Pantanal do Abobral/Nhecolândia). Para a aplicação dos formulários foram realizadas entrevistas in loco e via plataforma digital online. Para identificação do bugio enquanto espécie-bandeira foram utilizados critérios conforme literatura científica. Foram entrevistadas 106 pessoas, entre turistas e residentes da comunidade local. De acordo com os critérios adotados, pode-se dizer que A. caraya reúne vários atributos que a tornam espécie de alto valor para a conservação sistêmica do Pantanal. A mesma pode ser considerada uma das espécies-bandeira do Pantanal, emblemática para o ecoturismo e uso educacional, contribuindo para a formação de uma consciência socioambiental de proteção à biodiversidade em sua totalidade

PalaVras-Chave: Ecoturismo, Sustentabilidade, Espécies-bandeira.

\section{Abstract:}

The present work aims to evaluate how the howler monkey (Alouatta caraya) is inserted in the context of wildlife tourism in the Southern Pantanal and its recognition as a flag species. In addition to guiding recommendations for ecotourism in the Pantanal region. The study area covers the Pantanal region of Mato Grosso do Sul state. For data collection, a semi-structured form was applied to tourists who visited the Southern Pantanal and residents of the region of Passo do Lontra (Pantanal do Miranda) and Curva do Leque (Pantanal do Abobral/Nhecolândia). For the application of the form were conducted on-site interviews, in addition to the distribution for tourists in online digital platform. In order to identify the howler monkey as a flag species some criteria were considered as the scientific literature. The study resulted in 106 people interviewed among tourists and members of the local community. According to the adopted criteria, it can say that $A$. caraya presents several requirements that make it a high value species for systemic conservation of the Pantanal region. It can be considered one of the Pantanal's flagship species, being emblematic for ecotourism and educational use, contributing to the formation of a socio-environmental awareness of biodiversity protection in totality.

KEYWORDS: Ecotourism, Sustainability, Flagship species.

\section{RESUMEN:}


El presente trabajo tiene como objetivo evaluar cómo se inserta el mono aullador (Alouatta caraya) en el contexto del turismo de observación de vida salvage en el Pantanal del Sur y su reconocimiento como especie bandera, además de orientar las recomendaciones para el ecoturismo en la región del Pantanal. El área de estudio incluye la región del Pantanal de Mato Grosso do Sul. Para la recopilación de datos, se aplicó un formulario semiestructurado a los turistas que visitaron el Pantanal Sur y a los residentes locales de la región de Passo do Lontra (Pantanal do Miranda) y Curva do Leque (Pantanal do Abobral / Nhecolândia). Para la aplicación de los formularios, se realizaron entrevistas in loco, y a través de una plataforma digital en línea. Para la identificación del mono aullador, como especie bandera, se utilizaron criterios de acuerdo con la literatura técnica. Se entrevistó a 106 personas, incluidos turistas y miembros de la comunidad local. De acuerdo con los criterios adoptados, es posible decir que A. caraya cumple con varios requisitos que concuerdan con una especie de alto valor para la conservación sistémica del Pantanal. Puede ser considerada una de las especies banderas, emblemática para el ecoturístico y uso educativo, contribuyendo a la formación de una conciencia socio-ambiental de la protección de la biodiversidad en su totalidad.

Palabras Clave: Ecoturismo, Sustentabilidad, Especies bandera.

\section{INTRODUÇÃo}

O ecoturismo representa um novo paradigma do turismo. Sua essência implica o contato com a natureza, o zelo com os ambientes naturais e o respeito às comunidades visitadas, agregando-se aos vários símbolos de ações socioambientais amigáveis e para fins conservacionistas. O ecoturismo é considerado um dos segmentos do turismo que mais crescem no Brasil e no mundo. A Organização Mundial do Turismo (OMT) estima que, globalmente, $10 \%$ dos turistas se interessam por destinos protagonizados pela natureza (Filleto \& Macedo, 2015), portanto, relacionados ao ecoturismo.

Ainda que pressuponha rendimento financeiro dentre suas bases constituintes, o ecoturismo pode contribuir para salvaguardar a biodiversidade e conservar práticas culturais identitárias da relação sociedadenatureza. Todavia, há um limite a ser observado, atenta e criticamente, para que não se confunda espetacularização socioambiental com ecoturismo. Ribeiro (2018), adverte que a relação entre turismo e natureza não deve se basear em espetacularização, reflexo da acumulação de capital e do mercado globalizado. Apreende-se como um alerta aos empreendedores e demais atores sociais do turismo para que se faça uso sustentável da natureza com princípios éticos, com planejamento e manejo adequados dos ambientes naturais e seus elementos.

Durante muito tempo, e em várias partes do mundo, animais eram, e ainda o são, submetidos a muitos tipos de agressão, exploração e mesmo abatidos para o deleite do turista. Para o grupo dos primatas, Mittermeier (1987) apresenta um levantamento de casos ao redor do mundo sobre as motivações para o abate e outras formas de uso desses animais para o turismo, que vão desde a finalidade recreativa até exposição e comercialização ilegal. Tais atitudes e modelos de uso da biodiversidade exigiram transformações ao longo do tempo e o ecoturismo, a partir do turismo de observação de vida silvestre, tem ganhado seguidores dessa prática não consuntiva da fauna.

O turismo de observação de vida silvestre é um dos segmentos do ecoturismo baseado em avistamento e interação com a vida selvagem e tem alcançado popularidade em todo o mundo, seja pela interação histórica do ser humano com animais, seja pela preocupação com a conservação e a saúde do meio ambiente (Reynolds \& Braithwaite, 2001). Apesar da aproximação entre meio ambiente e turismo, os autores abordam que os valores de conservação, bem-estar animal, satisfação do visitante e lucratividade estão frequentemente em conflito, o que precisa ser refletido e mitigado. Por isso, gestores, empreendedores e demais atores dessa cadeia devem compreender a importância da conservação ambiental como prioritária e como requisito essencial da sustentabilidade do próprio empreendimento. Do contrário, o ecoturismo repetirá os mesmos modos de exploração dos bens naturais observados nas formas hegemônicas de produção.

Portanto, o ecoturismo enquanto novo paradigma do turismo está pautado em sustentabilidade e conservação. É um elo entre interação com a natureza, conhecimento e proteção de ambientes naturais, portanto uma prática aliada da conservação da sociobiodiversidade. Neste contexto, buscam-se estratégias 
que aprimorem as formas de geração de conhecimento e comunicação para que turistas e residentes, ao conhecerem a biodiversidade e nela se reconhecerem, possam valorizá-la e desejar sua conservação.

O Pantanal é apontado como um dos principais polos para o desenvolvimento do ecoturismo (Magalhães, 2001; Mamede \& Alho, 2004; Sabino \& Pivatto, 2007). Mamede e Alho (2004) apontam que turistas reconhecem os mamíferos como elementos fundamentais para o turismo de contemplação da natureza no Pantanal, sendo possível usufruir dos bens naturais de forma sustentável.

A planície pantaneira, uma das maiores planícies inundáveis do planeta, contempla em seu território muitos animais considerados espécies-bandeira, dentre as quais, a onça-pintada (Panthera onca), o jacaré (Caiman yacare), a arara-azul (Anodorhynchushyacinthinus), a anta (Tapirusterrestris), o tamanduá-bandeira (Myrmecophaga tridactyla), a ariranha (Pteronura brasiliensis) e o tuiuiú (Jabiru mycteria), este reconhecido como ave-símbolo do Pantanal, dentre outros animais carismáticos que simbolizam a região pantaneira (Conservação Internacional, 2003).

Espécies-bandeira são utilizadas em campanhas de sensibilização para proteger a biodiversidade de determinadas regiões ou territórios, cujas ações contribuem não somente para a proteção da espécie em si, mas de todas as espécies presentes regionalmente e seus respectivos habitats (Pádua, 1997; Buss, Lokschin, Setubal \& Teixeira, 2007; Vilas Boas \& Dias, 2010), numa abordagem ecossistêmica e de ecologia da paisagem. A adoção de espécies-bandeira tem o potencial de conectar ações de sensibilização (Buss et al., 2007) com as de comunicação socioambiental.

O uso do conceito de espécie-bandeira ou emblemática tem-se expandido com o propósito de motivar o envolvimento público em esforços de conservação. De modo abrangente, uma espécie-bandeira é popular, simpática ou carismática podendo ser utilizada como símbolo para despertar o interesse público por determinada espécie e seu hábitat e promover valores que redundem em conservação (Smith \& Sutton, 2008).

Esses mesmos atributos podem servir para fortalecer o ecoturismo por meio do turismo de observação de vida silvestre no âmbito dos territórios. Tal segmento tem revelado resultados favoráveis ao desenvolvimento turístico, à conservação da natureza, e, para que se alcance sustentabilidade efetiva, os princípios do ecoturismo devem ser respeitados e aplicados (Brumatti, 2013). Dentre esses princípios estão: a educação ambiental, o mínimo impacto sobre os ambientes naturais, a compatibilização entre a conservação da natureza e o respeito à diversidade social das áreas visitadas.

Primatas silvestres, de modo geral, exercem fascínio sobre as pessoas: são carismáticos, guardam semelhanças com a espécie humana e compõem o imaginário social, o que os tornam elementos de interesse ao turismo de observação de vida silvestre. De acordo com Ross e Wall (1992) e Peralta et al. (2019), os primatas estão entre os principais atrativos de contemplação no ecoturismo, especialmente em florestas tropicais.

O presente trabalho tem por objetivo avaliar como o bugio (Alouatta caraya) está inserido no contexto do turismo de observação de vida silvestre no Pantanal Sul e seu reconhecimento por atores sociais enquanto espécie-bandeira. Além disso, pretende-se oferecer subsídios científicos para o turismo de vida silvestre e pautar recomendações para o ecoturismo na região pantaneira.

\section{MÉtodos}

A área de estudo contempla a região do Pantanal no Mato Grosso do Sul (Pantanal Sul), Bacia Hidrográfica do Alto Paraguai (BAP). Para coleta de dados foi aplicado um formulário semiestruturado junto aos turistas que visitaram o Pantanal Sul (Passo do Lontra e fazenda Barranco Alto) e moradores locais das comunidades rurais do Passo do Lontra (Pantanal do Miranda) e da Curva do Leque (Pantanal do Abobral/Nhecolândia) (figura 1). 


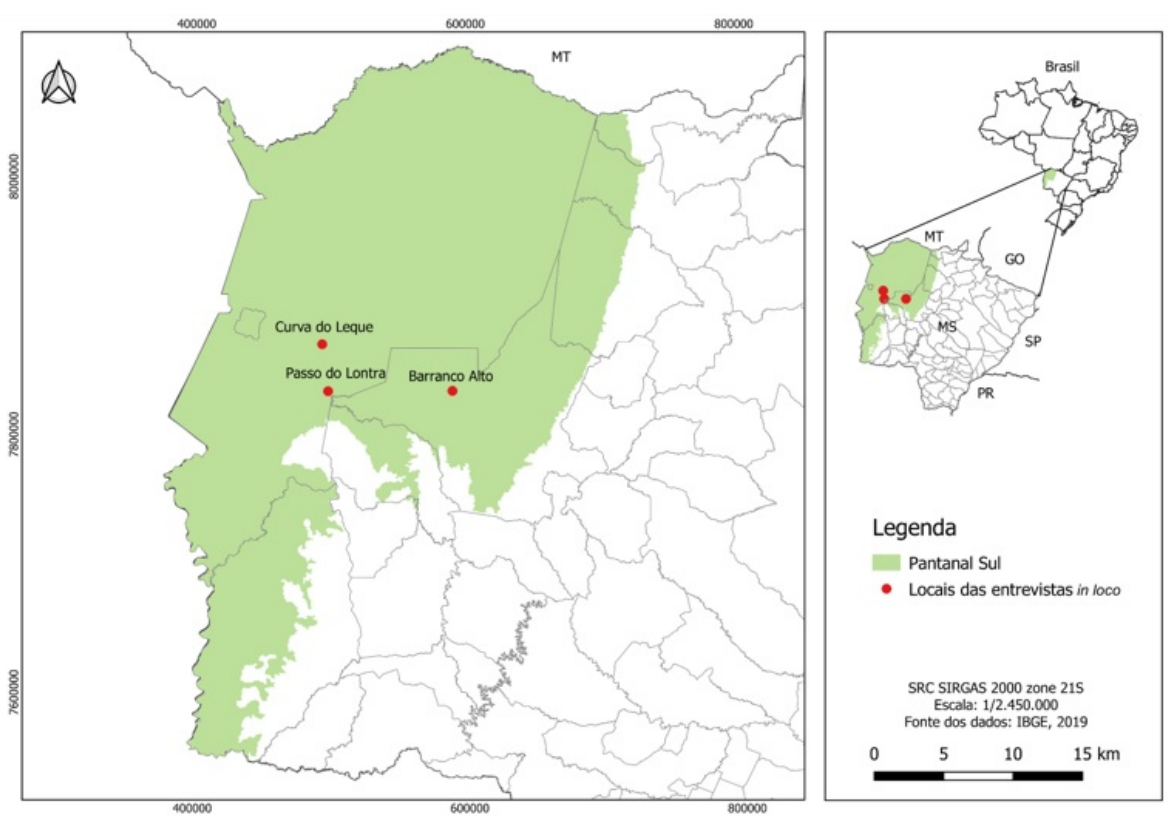

FIGURA 1

Delimitação do Pantanal no estado de Mato Grosso do Sul

(Pantanal Sul), com destaque aos locais das entrevistas in loco.

Fonte: autoras.

Para a aplicação dos formulários foram realizadas entrevistas in loco e via plataforma digital online, ambas no período de janeiro de 2018 a fevereiro de 2019. A partir das entrevistas e do preenchimento do formulário, foram levantados dados quali-quantitativos, tais como: quais primatas os turistas e moradores locais já observaram no Pantanal; o interesse em observar bugio (Alouatta caraya) em atividades turísticas no Pantanal; o interesse por pacotes turísticos exclusivos para observação de primatas no Pantanal; quais mamíferos de maior interesse para o turismo de observação de vida silvestre; quais elementos poderiam contribuir para aprimorar o turismo de observação de bugio e de outros primatas; qual o nível de conhecimento sobre a história natural e os serviços ecossistêmicos desempenhados pelo bugio; qual o nível de reconhecimento do bugio (Alouatta caraya) enquanto espécie-bandeira, entre outras informações pertinentes. O projeto foi submetido e aprovado pelo comitê de ética sob o registro CAAE 06822919.0.0000.5161.

Para identificação do bugio, enquanto espécie-bandeira, foram utilizados critérios considerados por Bowen-Jones e Entwistle (2002) e Buss et al. (2007), sendo os quais: distribuição geográfica, status de conservação, papel ecológico, nível de reconhecimento, associações positivas, conhecimento tradicional, carisma, significância cultural, uso existente e nomes populares.

\section{Resultados e Discussão}

Foram entrevistadas 106 pessoas entre turistas e integrantes da comunidade na região do Pantanal. Destes, $73,6 \%(n=78)$ foram turistas (visitantes do Pantanal) e 26,4\% $(n=28)$ foram moradores do Passo do Lontra e da Curva do Leque no Pantanal Sul (figura 2).

Dentre as Unidades Federativas de origem dos turistas estiveram: São Paulo (SP), Distrito Federal (DF), Minas Gerais (MG), Mato Grosso do Sul (MS), Amazonas (AM), Rio Grande do Sul (RS) e Paraná (PR). Também participaram da pesquisa turistas estrangeiros oriundos de Washington, Virgínia, Arizona e Texas (USA), Tierra del Fuego (Argentina) e Norfolk (Reino Unido).

Quando questionados sobre quais primatas já observaram no Pantanal, 52\% $(n=55)$ dos turistas informaram terem avistado exclusivamente bugios; $14 \%(\mathrm{n}=15)$ já avistaram bugio e macaco-prego (Sapajus cay); 10,4\% ( $\mathrm{n}=11)$ já observaram bugio e as outras espécies regionalmente ocorrentes como mico-de-cauda- 
preta (Mico melanurus), macaco-da-noite (Aotus azarae) e zogue-zogue (Callicebus cf.pallescens); 9,4\% ( $\mathrm{n}=$ 10) não conheciam e não avistaram primatas em visita ao Pantanal; $6,6 \%(\mathrm{n}=7)$ viram somente macacoprego (Sapajus cay). Cabe destacar que um turista pescador oriundo do sudeste brasileiro afirmou ter visto sagui (Callithrix sp.), mas confessou não ter certeza de qual espécie se tratava especificamente (Figura 2).

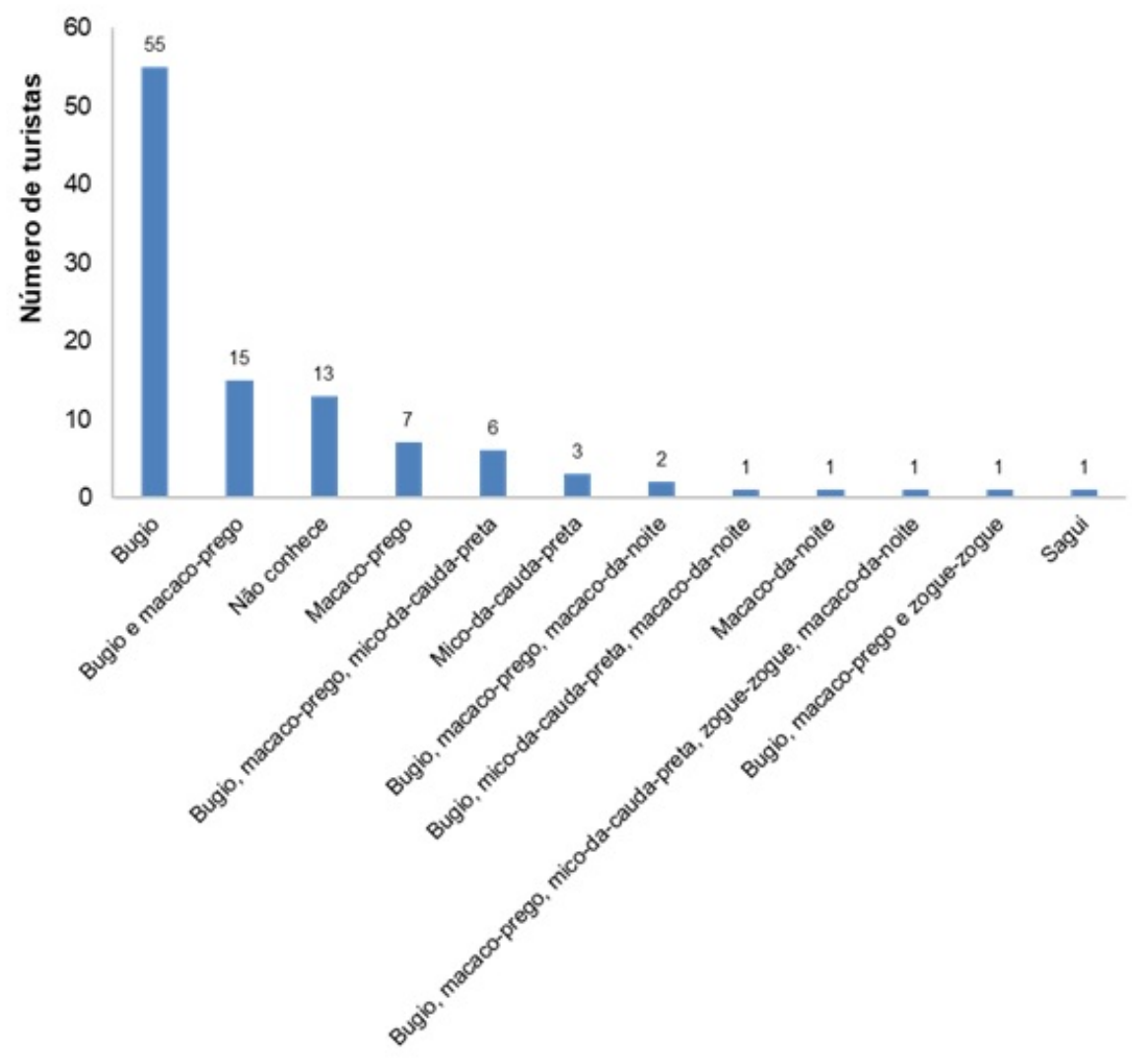

FIGURA 2

Espécies conhecidas e avistadas pelos turistas e comunidade no Pantanal Sul.

A comunidade, por sua vez, em sua maioria $(86 \%, \mathrm{n}=24)$ afirmou conhecer apenas o bugio (A. caraya), enquanto primata na planície pantaneira; dois moradores (7\%) responderam terem observado mico-decauda-preta (Mico melanurus) durante passeio de barco pelo rio Paraguai; um afirmou ter avistado macacoprego $(S$. cay) na margem do rio Miranda; e outro morador $(\mathrm{n}=1)$ afirmou ter registrado além do bugio (A. caraya), o zogue-zogue (Callicebus cf.pallescens), o macaco-prego (S. cay) e o mico-de-cauda-preta (Mico melanurus) em área próxima à morraria do Urucum, em Corumbá/MS.

Vale destacar que na percepção dos dois grupos avaliados, turistas e residentes, o bugio é a espécie que se sobressai nas respostas. No entanto, pela mobilidade dos turistas, a possibilidade de avistamento de outros primatas da região é maior. De fato, nas sub-regiões do Pantanal do Miranda, Abobral e Nhecolândia, onde as entrevistas foram realizadas com moradores, o bugio é o primata mais comum, além disso, o som emitido o deixa facilmente perceptível, notadamente por meio da audição. Os primatas mencionados pelos respondentes, de modo geral, coincidem com o mapa de distribuição dessas espécies na região do Pantanal, conforme Reis et al. (2008).

De acordo com os critérios sugeridos por Bowen-Jones e Entwistle (2002) e Buss et al. (2007), pode-se dizer que $A$. caraya reúne vários requisitos que a tornam espécie de alto valor para a conservação sistêmica do Pantanal (Quadro 1). 


\section{QUADRO 1}

O bugio (A. caraya) como espécie-bandeira segundo critérios adotados por Bowen-Jones e Entwistle (2002) e Buss et al. (2007).

\begin{tabular}{|c|c|c|}
\hline \multicolumn{2}{|r|}{ Critérios } & Características \\
\hline 1 & Distribuição geográfica & $\begin{array}{l}\text { Ampla distribuição no Pantanal e de } \\
\text { fácil observação }\end{array}$ \\
\hline 2 & Status de conservação & $\begin{array}{l}\text { Quase ameaçado (ICMBio, 2018); } \\
\text { IUCN, 2018) }\end{array}$ \\
\hline 3 & Papel ecológico & $\begin{array}{l}\text { Espécie-chave para os ecossistemas, } \\
\text { dispersor de sementes (semeador de } \\
\text { floresta) e indicador de hábitat } \\
\text { florestal }\end{array}$ \\
\hline 4 & Reconhecimento & $\begin{array}{l}\text { Bastante conhecido pela } \\
\text { comunidade local e de interesse dos } \\
\text { turistas }\end{array}$ \\
\hline 5 & Uso preexistente & $\begin{array}{l}\text { No passado foi utilizado para } \\
\text { produção das cordas da viola de } \\
\text { cocho e na confecção de flechas por } \\
\text { indigenas. Atualmente é elemento } \\
\text { contemplativo para o turismo }\end{array}$ \\
\hline 6 & Carisma & $\begin{array}{l}\text { Considerado carismático pela } \\
\text { comunidade e turistas }\end{array}$ \\
\hline 7 & Significado cultural & $\begin{array}{l}\text { Presente na cultura popular como } \\
\text { músicas regionais, contos e lendas }\end{array}$ \\
\hline 8 & Associações positivas & $\begin{array}{l}\text { Associado a indicador climático e de } \\
\text { áreas conservadas }\end{array}$ \\
\hline 9 & Conhecimento tradicional & $\begin{array}{l}\text { O som emitido é rapidamente } \\
\text { identificado pela comunidade. A } \\
\text { mesma reconhece o bugio enquanto } \\
\text { semeador de floresta e conhece seus } \\
\text { hábitos sociais e sazonais }\end{array}$ \\
\hline 10 & Nomes populares & $\begin{array}{l}\text { bugio, bugio-preto, } \\
\text { macaco-roncador, carayá (em } \\
\text { guarani), carayá hú (macho), } \\
\text { carayá bayo (fêmea) }\end{array}$ \\
\hline
\end{tabular}

As autoras

Enquanto mamíferos de interesse para o turismo de observação de vida silvestre, numa escala gradativa de 1 a 5 - sendo 1 grau menos significante e 5 altamente significante - o bugio ( $A$. caraya) foi definido como altamente significante para 58\% $(\mathrm{n}=61)$ dos entrevistados. A onça-pintada (Panthera onca) foi reconhecida como altamente significante por $85 \%(\mathrm{n}=99)$ dos participantes, resultado que corrobora os estudos de Mamede e Alho (2004), Caruso e Pérez (2013), Tortato e Izzo (2017) que apontam o reconhecimento popular da onça-pintada. Já as espécies como: quati (Nasua nasua), capivara (Hydrochaerus hydrochaeris) e queixada (Tayassu pecari) foram consideradas menos atrativas para o turismo de observação de vida silvestre (Tabela 1). No entanto, tais espécies, assim como as demais, são igualmente importantes para a manutenção das redes de interação ecológicas e para o equilíbrio dinâmico dos ecossistemas. Depreende-se a necessidade de qualificação do ecoturismo para comunicar informações socioambientais sobre a biodiversidade e promover educação ambiental de forma abrangente. 
TABELA 1.

Grau de atratividade de mamíferos para o turismo de observação de vida selvagem na visão de turistas e integrantes da comunidade

\begin{tabular}{|c|c|c|c|c|c|c|}
\hline $\begin{array}{l}\text { Mamíferos de } \\
\text { interesse ao turismo }\end{array}$ & $1^{\circ} \mathrm{grau}$ & $2^{\circ} \mathrm{grau}$ & $3^{\circ} \mathrm{grau}$ & $4^{\circ} \mathrm{grau}$ & $5^{\circ} \mathrm{grau}$ & $\begin{array}{l}\text { não } \\
\text { respondeu }\end{array}$ \\
\hline anta & 7 & 9 & 10 & 11 & 69 & \\
\hline ariranha & 8 & 7 & 16 & 12 & 58 & 5 \\
\hline bugio & 5 & 6 & 15 & 19 & 61 & \\
\hline capivara & 27 & 13 & 26 & 7 & 32 & 1 \\
\hline cervo-do-pantanal & 4 & 9 & 10 & 10 & 73 & \\
\hline jaguatirica & 2 & 7 & 3 & 9 & 78 & 7 \\
\hline lontra & 4 & 7 & 11 & 15 & 59 & 10 \\
\hline onça-pintada & 1 & 0 & 1 & 5 & 99 & \\
\hline quati & 22 & 14 & 26 & 10 & 29 & 5 \\
\hline queixada & $-\frac{5}{13}$ & 11 & 30 & -10 & 42 & \\
\hline
\end{tabular}

As autoras

Se analisado sob a perspectiva exclusiva dos turistas, o grau de atratividade do bugio (A. caraya) aumenta para $64 \%$ e na visão da comunidade esta percepção diminuiu para 39,2\%. Possivelmente, o menor reconhecimento de atratividade pela comunidade residente pode estar relacionado ao fato de o bugio estar presente no cotidiano e a raridade, neste contexto, desempenha importante papel na dimensão valorativa.

Após a explicação sobre o conceito de espécie-bandeira, $45 \%$ dos entrevistados, incluindo turistas e residentes, afirmaram que o bugio é uma das espécies-bandeira do Pantanal ou pode vir a sê-lo. No entanto, $43 \%$ não o consideraram, $9 \%$ não responderam e $3 \%$ não souberam definir.

Sobre o reconhecimento do bugio como dispersor de sementes e espécie importante na restauração florestal e demais funções ecológicas, observou-se que $82 \%$ da comunidade residente tem a percepção do papel do bugio nesses processos, enquanto $68 \%$ dos turistas possuem essa mesma percepção. Para o turista, o bugio representa mais como um elemento de apelo estético-paisagístico e de presença do que funcional (ecológico). Outros atributos por eles reconhecidos foram: indicador de áreas mais conservadas, um significativo elemento contemplativo por ter um "hábito tranquilo" (ou seja, não apresenta comportamento agressivo frente à presença humana), fácil detecção devido ao som emitido com alcance a quilômetros de distância.

A aparente contradição dos resultados, ou seja, ao mesmo tempo em que o bugio é considerado muito importante nos processos de manutenção do funcionamento dos ecossistemas não é visto como espéciebandeira para $43 \%$ dos entrevistados, reflete como a racionalidade técnica opera na sociedade. Terminologias e conceitos técnicos são utilizados e compreendidos por grupos específicos, neste caso, pesquisadores e cientistas. No entanto, a maioria dos entrevistados, turistas e residentes, admitem a importância do bugio sem adoção de nomenclaturas científicas. Ainda que a linguagem adotada seja diferente, ambos os grupos compreendem a importância do bugio e isso favorece o diálogo de saberes e a proposição de adotá-lo como espécie-bandeira.

O papel desempenhado pelo bugio na percepção dos entrevistados é corroborado por Gordo et al. (2008), os quais afirmam que os primatas desempenham um importante papel na manutenção e regeneração de florestas tropicais, além de serem importantes indicadores de qualidade ambiental e constituírem componente fundamental na definição de estratégias de conservação nos biomas, regiões e países. 
Algumas espécies, como o bugio (A. caraya), são muito importantes na manutenção de ecossistemas, sendo conhecidas como espécies-chave, as quais desempenham função determinante na estrutura, saúde e funcionamento dos ecossistemas e a sua perda deve impactar significativamente a população de outras espécies no ecossistema (Buss et al., 2007, Gordo et al., 2008, Peralta et al., 2019).

Gostar de observar bugio na região do Pantanal é praticamente unânime entre os entrevistados 99\% ( $\mathrm{n}=$ 105). Apenas um turista afirmou não saber porque nunca presenciou na natureza, por isso não soube definir.

Dentre os sentimentos vivenciados diante do avistamento de bugio, destacaram-se de forma similar: alegria, encantamento e curiosidade. No entanto, foram mencionadas, ainda que de forma inexpressiva, o medo $(n=2)$ e a indiferença $(n=2)$. Ressalta-se que as duas pessoas que afirmaram sentir indiferença ao ver bugio são integrantes da comunidade e o bugio é considerado por eles como um elemento do cotidiano (figura $3)$.

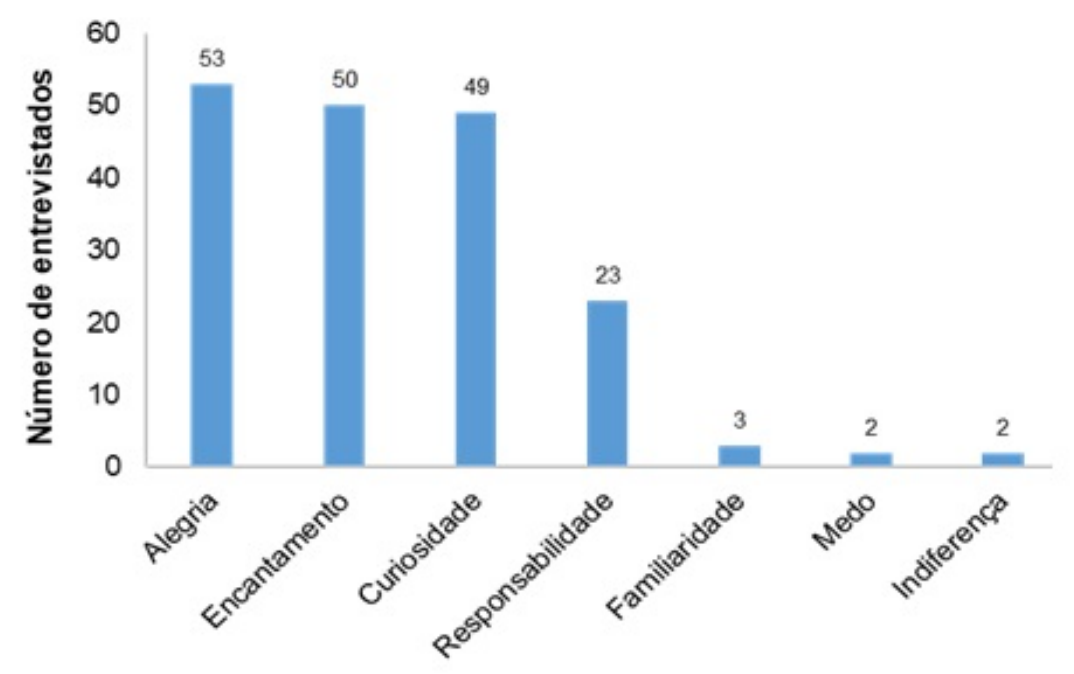

FIGURA 3.

Sentimentos vivenciados diante do avistamento de bugio no Pantanal apontados pelos entrevistados As autoras

Apesar de o bugio ser considerado uma espécie quase ameaçada de extinção no Brasil, o mesmo apresenta expressiva abundância e de fácil detecção no Pantanal. A presença de bugio nos roteiros de ecoturismo oferecidos no Pantanal pode influenciar na sensibilização dos visitantes melhorando sua relação com o ambiente contribuindo, também, na conservação dos elementos naturais em escala regional e em longo prazo, visto que sua posição trófica na cadeia alimentar e participação na rede de interações favorece amplamente a manutenção da auto-organização das comunidades biológicas e integridade dos serviços ambientais.

Entre os instrumentos considerados mais relevantes para turistas e moradores do Pantanal Sul para o incremento do turismo de observação de primatas estão: guia ilustrado sobre primatas do Pantanal; qualificação de profissionais guias e condutores; existência de mapa de distribuição das espécies de primatas; e oferta de roteiros específicos sobre primatas (Tabela 2). 
TABELA 2.

Grau de importância de ferramentas subsidiárias ao turismo de observação de primatas na região do Pantanal Sul

\begin{tabular}{|c|c|c|c|c|c|c|}
\hline \multirow{2}{*}{$\begin{array}{l}\text { Ferramentas } \\
\text { subsidiárias ao } \\
\text { turismo de } \\
\text { observação de } \\
\text { primatas }\end{array}$} & \multicolumn{5}{|c|}{ Graus } & \multirow{2}{*}{$\begin{array}{l}\text { Não } \\
\text { respondeu }\end{array}$} \\
\hline & 1 & 2 & 3 & 4 & 5 & \\
\hline $\begin{array}{l}\text { Conhecer o som da } \\
\text { espécie }\end{array}$ & 7 & 8 & 23 & 12 & 50 & 6 \\
\hline $\begin{array}{l}\text { ter mapa de } \\
\text { distribuição dos } \\
\text { primatas }\end{array}$ & 7 & 7 & 23 & 13 & 51 & 5 \\
\hline $\begin{array}{l}\text { Guia ilustrado de } \\
\text { primatas }\end{array}$ & 2 & 5 & 13 & 13 & 70 & 3 \\
\hline $\begin{array}{l}\text { Roteiros específicos } \\
\text { para observação de } \\
\text { primatas }\end{array}$ & 2 & 7 & 26 & 21 & 48 & 2 \\
\hline $\begin{array}{l}\text { Guia de turismo } \\
\text { qualificado }\end{array}$ & 2 & 1 & 19 & 13 & 66 & 5 \\
\hline $\begin{array}{l}\text { Pacotes turísticos } \\
\text { para observação de } \\
\text { primatas }\end{array}$ & 3 & 15 & 25 & 13 & 45 & 5 \\
\hline
\end{tabular}

Dos turistas entrevistados, 46,2\% demonstraram interesse em pacotes exclusivos para observação de primatas. Apesar de a observação de primatas em áreas naturais brasileiras ser exercida de forma ocasional, em meio a outras práticas de lazer dos visitantes (Oliveira, 2007), existem casos como o relatado por Sabbatini et al. (2006) em que pelo menos 10\% e 3\% dos visitantes de final de semana e dias da semana, respectivamente, visitam o Parque Nacional de Brasília para observação de macaco-prego (Cay libidinosus).

Há exemplos como da Reserva de Desenvolvimento Sustentável de Mamirauá na Amazônia onde é possível encontrar em trilhas pelo menos quatro das espécies de primatas de ocorrência na região. Paim et al. (2012) afirmam que o turismo realizado na área é de baixo impacto, a presença dos turistas não afugenta os primatas e o uso constante das trilhas aumenta a detectabilidade de indivíduos, possibilitando um turismo harmônico com a natureza. Peralta et al. (2019) afirmam que estudos sobre densidades populacionais de primatas associados ao monitoramento do uso das trilhas e outras práticas socioambientais em Mamirauá têm alcançado resultados importantes sugerindo que se trata de atividade não extrativa e sustentável.

A região como Bali, na Indonésia, é exemplo de que o turismo de observação de primatas associado ao respeito pela cultura local tem viabilidade e pode contribuir para a conservação de um território. A Floresta dos Macacos é reconhecida como notável exceção de declínio da população do macaco-de-cauda-longa (Macaca fascicularis), a comunidade local protege flora e fauna promovendo valores religiosos tradicionais hindus e o turismo na Floresta dos Macacos (Wheatley \& Putra, 1994). Há exemplos também como da aldeia Bigodi na Uganda, onde a principal atração é uma área úmida florestada gerenciada por uma cooperativa de turismo local, na qual os turistas são guiados pela região pantanosa em busca de observação de primatas e aves tropicais (Lepp, 2007). Tais iniciativas demonstram que o turismo de observação de primatas pode ser um investimento promissor que une desenvolvimento local à conservação de espécies e seus respectivos habitats.

Mesmo com várias campanhas informativas e de sensibilização no Brasil, 10\% ( $\mathrm{n}=11)$ dos entrevistados, ainda, acreditam que o bugio seja transmissor de febre-amarela, o que indica a necessidade de trabalho educativo e informativo contínuos de sensibilização, orientação e esclarecimentos, com base científica, para assegurar o melhor entendimento da comunidade e a proteção dessa espécie e de toda a biodiversidade local. Brumatti (2013), considera que para o turismo de observação de vida silvestre há necessidade de capacitação 
profissional em todos os níveis e participação direta do poder público na ativação de códigos de conduta ética, diretrizes e desenvolvimento de melhores práticas. Essa qualificação deve envolver tanto informações verdadeiras sobre as espécies como métodos de observação, proteção e manejo adequado, limitando, por exemplo, o emprego de tecnologias como drones, e outros, de modo a evitar a aproximação exagerada aos animais, a pretexto de ecoturismo, conforme foi observado durante a pesquisa.

O bugio ( $A$. caraya) é uma espécie frugívora, folívora, reconhecida como importante dispersora de sementes e compõe uma rede de interação essencial ao equilíbrio dinâmico dos ambientes onde habita. A espécie contribui em inúmeros serviços ambientais a partir da dispersão de sementes e manutenção das florestas, as quais provêm alimento, controle térmico e regulação climática, qualidade do ar, regulação do ciclo da água, entre outros. Portanto, o bugio pode ser considerado espécie-chave dos ecossistemas. Enquanto elemento de contemplação do ecoturismo é reconhecido como um atrativo natural do turismo de observação de vida silvestre. Na perspectiva do turismo e da sustentabilidade, a proteção desta espécie, por exemplo, é uma forma de assegurar o estabelecimento e manutenção de processos naturais. Todos esses elementos permitem vislumbrar a presença do bugio como um indicador de sustentabilidade na região do Pantanal em perspectiva sistêmica (Figura 4).

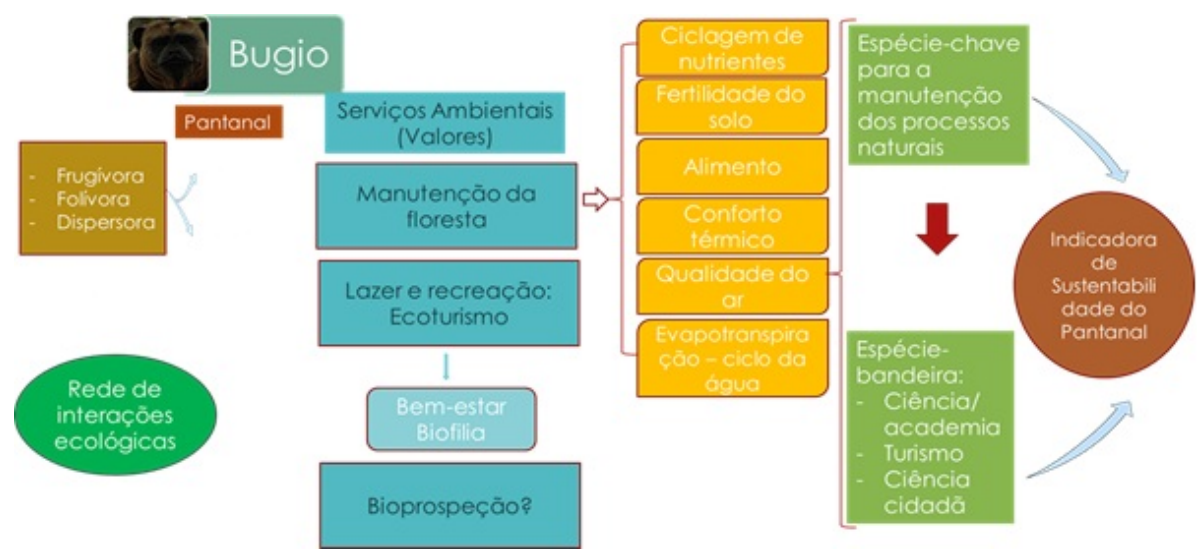

FIGURA 4.

Diagrama sobre as interrelações possíveis entre bugio (A. caraya) e os processos socioambientais autoras

A prática da ciência cidadã em atividades ecoturísticas tem sido ferramenta importante na formação e engajamento de pessoas, enquanto agentes de proteção e conservação da natureza e na construção do conhecimento, uma vez que a ciência cidadã é instrumento de retroalimentação positiva na geração de conhecimento científico sobre a biodiversidade (Mamede, Benites \& Alho, 2017).

Ainda neste contexto, o turismo tem sido amplamente utilizado como uma estratégia de conservação que pode beneficiar diretamente a população local contribuindo para o desenvolvimento e criando incentivos de conservação dos ambientes naturais. Xiang (2011) sugere que a presença de espécies emblemáticas em determinados locais pode resultar em ativos para angariar fundos e criar publicidade para os propósitos de conservação.

Nos países tropicais e especialmente na América Latina, a exuberância da biodiversidade é inegável. Portanto, a cultura de valorização dessa riqueza natural e reconhecimento de sua potência seria bastante sensato para condução de territórios sustentáveis. No entanto, por movimentos do capital, o que se percebe é a pressão cada vez crescente sobre os bens naturais, com incessante tentativa de uniformização dos modos de produção. Por essa reflexão, mais uma vez o universal se expressa e se alimenta do singular.

\section{Considerações Finais}

A representação simbólica de espécie-bandeira contribui para a finalidade de ancoragem de propostas de conservação. No Pantanal, o bugio se revela como importante elemento contemplativo para o turismo 
de observação de vida silvestre, podendo contribuir em processos de conservação, pautado nos diversos saberes, educação ambiental e na ciência cidadã. $\mathrm{O}$ mesmo pode ser considerado uma das espécies-bandeira do Pantanal, sendo emblemático para o ecoturismo bem como para atividades educativas, de estímulo à formação de uma consciência socioambiental e de proteção à sociobiodiversidade em sua totalidade.

Constata-se que existe uma boa aceitação para a prática de turismo de observação de primatas do Pantanal, no entanto, mesmo tendo demanda e certo avanço do turismo de observação de vida silvestre, ainda há necessidade de qualificação a partir de planejamento, materiais de apoio, regramento e orientação com normas eficientes e claras sobre o uso da biodiversidade no turismo. Nisto se inclui o uso de tecnologias, como os drones, que demandam diretrizes para monitoramento de impactos potenciais e definição de distâncias mínimas do observador com a espécie observada. Há necessidade de políticas públicas para o estabelecimento e manutenção deste modelo de turismo que assegure sustentabilidade local, conservação das espécies e manutenção da vida.

A percepção dos moradores sobre o bugio, seus hábitos e história natural, descreve a realidade socioambiental na qual estão inseridos e a maioria valoriza a presença dessa espécie, sendo esta também a percepção dos turistas. Os resultados sustentam a proposta de ser o bugio uma espécie-bandeira no Pantanal. Ressalta-se a importância de trabalhos em parceria entre pesquisadores da área de biologia da conservação e gestores da área de turismo para unir esforços que propiciem benefícios econômicos e conservação ambiental de forma integrada. A integração de cientistas com a comunidade também se faz importante para a atuação de cientistas cidadãos, uma vez que, na integração de saberes, podem contribuir com a comunicação qualificada, para desmistificar o conhecimento sobre o bugio e elevar o apreço por essa e outras espécies.

Observa-se a necessidade de qualificação contínua de equipes e comunidades envolvidas a respeito do turismo com perspectivas de qualidade socioambiental e territórios sustentáveis.

\section{REFERÊNCIAS}

Bowen-Jones, E., \& Entwistle, A. (2002). Identifying appropriate flagship species: the importance of culture and local contexts. Oryx, 36(2), p. 189-195, 2002.

Brumatti, P. N. M. (2013). O papel do turismo de observação da vida selvagem para a conservação da natureza. Revista Brasileira de Ecoturismo, 6(4), 191-208

Buss, G.; Lokschin, L. X., Setubal, R. B., \& Teixeira, F. Z. (2007). A abordagem de espécie-bandeira na educação ambiental: estudo de caso do bugio-ruivo (Alouatta guariba) e o programa macacos urbanos. In: C. Gorczevski, C. (Org.). Direitos Humanos, Educação e Meio Ambiente. (pp. 165-185). Evangraf.

Caruso, F., \& Pérez, I. J. (2013). Tourism, local pride, and attitudes towards the reintroduction of a large predator, the jaguar Panthera onca in Corrientes, Argentina. Endangered Species Research, 21(3), 263-272.

Conservation International - Brasil (2003). Grandes regióes naturais: as últimas áreas silvestres da terra. Conservation International Brasil.

ICMBio. Instituto Chico Mendes de Conservação da Biodiversidade. (2018). Livro vermelho da fauna brasileira ameaçada de extinção. v. II: mamíferos. Brasília: ICMBio/MMA.

IUCN. International Union for Conservation of Nature and Natural Resources (2018). The IUCN Red List of Threatened Species. Recuperado de: https://www.iucnredlist.org/resources/categories-and-criteria

Filetto, F., \& Macedo, R. L. G. (2015). Desenvolvimento de indicadores de sustentabilidade para o ecoturismo em unidades de conservação. Revista Brasileira de Ecoturismo, 8(1), 11-30.

Gordo, M., Rodrigues, F., Vidal, M. D., \& Spironello, W. R. (2008). Primatas. (39-49) In: M. L. Oliveira, F. B. Baccaro, R. Braga-Neto, W. E. Magnusson (Eds.) Reserva Ducke: a biodiversidade amazônica através de uma grade. INPA.

Lepp, A. (2007). Residents' attitudes towards tourism in Bigodi village, Uganda. Tourism management, 28(3), 876-885.

Magalhães, G. W. (2001). Polos de ecoturismo: planejamento e gestão. Terragraph. 
Mamede, S. B., \& Alho, C. J. R. (2004). Turismo de contemplação de mamíferos do Pantanal: alternativa para o uso sustentável da fauna. In: Anais do IV Simpósio sobre Recursos Naturais e Sócio-econômicos do Pantanal. Empresa Brasileira de Pesquisa Agropecuária (Embrapa) Pantanal, Corumbá, Brasil. https://www.researchgate.net/profile/Cleber-Alho/ publication/237698923_Turismo_de_contemplacao_de_mamiferos_do_Pantanal_alternativa_para_o_uso_sustentavel_da links/56464ee908ae451880aa4817/Turismo-de-contemplacao-de-mamiferos-do-Pantanal-alternativa-para-ouso-sustentavel-da-fauna.pdf

Mamede, S., Benites, M., \& Alho, C. J. R. (2017). Ciência cidadã e sua contribuição na proteção e conservação da biodiversidade na reserva da biosfera do Pantanal. Revista Brasileira de Educação Ambiental, 12(4), 153-164.

Mittermeier, R. A. (1987). Conservation of Primates and their habitats. Primate societies, 477-490.

Oliveira, D. G. R. Impactos da visitação turística sobre animais em áreas naturais. (2007). [Monografia de especialização, UnB]. Brasília, DF, Brasil. http://dx.doi.org/10.26512/2007.TCC.180

Padua, S. M. (1997). Uma pesquisa em educação ambiental: a conservação do mico-leão-preto (Leontopithecus chrysopygus). In: C. Valladares-Padua, \& R. E. Bodmer (Orgs.). Manejo e conservação de vida silvestre no Brasil. (pp. 34-42). CNPq: Sociedade Civil Mamirauá.

Paim, F. P., Aquino, S. P., \& Valsecchi, J. (2012). Does ecoturism activity affect primates in Mamirauá Reserve? Uakari, $8(2), 41-48$

Peralta, N., El Bizri, H. R., Paim, F. P., \& Valsecchi, J. (2019). Mamirauá Reserve: Primate-based flooded forest conservation in the Amazon. In: K. Nowak, A. A. Barnett, \& I. Matsuda (Eds.). Primates in flooded forests: Ecology and Conservation. (pp. 326-330). Cambridge University Press. https://www.mamiraua.org.br/ documentos/f60909fc9e1210932db810ededfc006f.pdf

Reis, N. R., Peracchi, A. L., Pedro, W. A., \& Lima, I. P. (2011). Mamiferos do Brasil. 2ed. N. R. Reis

Reynolds, P. C., \& Braithwaite, D. (2001). Towards a conceptual framework for wildlife tourism. Tourism management, 22(1), 31-42.

Ribeiro, M. A. (2018). A espetacularização da natureza no Pantanal. Interações, 19(4), 803-812.

Ross, S., \& Wall, G. (1999). Evaluating ecotourism: the case of North Sulawesi, Indonesia. Tourism management, 20(6), 673-682.

Sabbatini, G., Satammati, M., Tavares, M. C. H., Giuliani, M. V., Visalberghi, E. (2006). Interactions between humans and capuchin monkeys (Cebus libidinosus) in the Parque Nacional de Brasília, Brazil. Applied Animal Behaviour Science, 97(2-4), 272-283.

Sabino, J., \& Pivatto, M. A. C. (2007). Infraestrutura receptiva para o turismo de observação de aves no Pantanal Sul e Planalto da Bodoquena, Mato Grosso do Sul. Observatório de Inovação do Turismo - Revista Acadêmica, 2(4), $1-11$.

Smith, A. M., \& Sutton, S. G. (2008). The role of a flagship species in the formation of conservation intentions. Human Dimensions of Wildlife, 13(2), 127-140.

Tortato, F. R., \& Izzo, T. J. (2017). Advances and barriers to the development of jaguar-tourism in the Brazilian Pantanal. Perspectives in Ecology and Conservation, 15(1), 61-63.

Vilas Boas, M. H. A., \& Dias, R. (2010). Biodiversidade e turismo: o significado e importância das espécies-bandeira. Turismo \& Sociedade, 3(1), 91-114.

Walpole, M. J., \& Leader-Williams, N. (2002). Tourism and flagship species in conservation. Biodiversity and conservation, 11(3), 543-547.

Wheatley, B. P., \& Putra, D. K. H. (1994). The effects of tourism on conservation at the monkey forest in Ubud, Bali. Revue d'écologie, 49(3), 245-267.

Xiang, Z. F., Yu, Y., Yang, M., Yang, J. Y., Niao, M. Y., \& Li, M. (2011). Does flagship species tourism benefit conservation? A case study of the golden snub-nosed monkey in Shennongjia National Nature Reserve. Chinese Science Bulletin, 56(24), 2553-2558. 